\title{
Bilateral atypical femoral shaft fractures and bisphosphonate therapy; a case report
}

Volume 8 Issue 3 - 2017

\section{Introduction}

There have recently been an increasing number of reports of atypical femoral fractures (AFFs) in patients on long term bisphosphonate (BP) therapy. ${ }^{1-3}$ BPs are potent inhibitors of osteoclast-mediated bone resorption and are widely recommended agents for the treatment of osteoporosis. ${ }^{4,5}$ However, the reported link between long term use of BPs and AFFs led to the appointment of a task force of the American Society for Bone and Mineral Research to address key questions related to this. ${ }^{6}$ They defined major and minor features for AFFs, where all major features must be present to define the femoral fracture as atypical (Table 1). AFF, associated wth BPs, are typically described in the subtrochanteric region of the femur and are usually unilateral on presentation. We present a case of bilateral atypical femoral fractures occurring in the shafts of the femori secondary to long term ibandronic acid therapy.

Table I Diagnostic criteria for atypical femoral fracture (Task force for the American Society for Bone and Mineral Research). ${ }^{16}$ Diagnosis requires the presence of all the major criteria. None of the minor criteria is required, but they may be present concomitantly with major criteria

\begin{tabular}{|c|c|c|}
\hline Major Criteria & Minor Criteria & Exclusion Criteria \\
\hline Proximal fracture & & \\
\hline $\begin{array}{l}\text { line under the lesser } \\
\text { trochanter and distal } \\
\text { fracture line above the } \\
\text { femoral condyles }\end{array}$ & \multicolumn{2}{|c|}{$\begin{array}{l}\text { Periosteal reaction along } \\
\text { the lateral cortex }\end{array}$} \\
\hline $\begin{array}{l}\text { No trauma or low-energy } \\
\text { trauma }\end{array}$ & $\begin{array}{l}\text { Increased cortical } \\
\text { thickness }\end{array}$ & $\begin{array}{l}\text { Intertrochanteric } \\
\text { fracture with extension } \\
\text { to the subtrochanteric } \\
\text { femur }\end{array}$ \\
\hline $\begin{array}{l}\text { Transverse or only slightly } \\
\text { oblique fracture line (angle } \\
<30^{\circ} \text { ) }\end{array}$ & $\begin{array}{l}\text { Prodromal pain in the } \\
\text { groin or thigh }\end{array}$ & Periprosthetic fracture \\
\hline Non comminuted fracture & Bilateral fracture & $\begin{array}{l}\text { Pathological fracture } \\
\text { related to a primary } \\
\text { bone tumor or bone } \\
\text { metastasis }\end{array}$ \\
\hline $\begin{array}{l}\text { Complete fracture crossing } \\
\text { from one cortex to the } \\
\text { other, with or without a } \\
\text { medial cortical beak or } \\
\text { incomplete fracture (or } \\
\text { fissure) involving only the } \\
\text { outer cortex }\end{array}$ & Delayed healing & - \\
\hline- & $\begin{array}{l}\text { Co-morbidities: } \\
\text { rheumatoid arthritis, } \\
\text { vitamin D deficiency, } \\
\text { hypophosphatasia }\end{array}$ & - \\
\hline- & $\begin{array}{l}\text { Concomitant } \\
\text { treatments: } \\
\text { bisphosphonates, } \\
\text { glucocorticoids, proton } \\
\text { pump inhibitors }\end{array}$ & - \\
\hline
\end{tabular}

\author{
Morrissey L, Memon AR, Glynn A \\ Department of Trauma and Orthopaedics, Waterford Regional \\ Hospital Ireland, Republic of Ireland
}

Correspondence: Aaron Glynn, Department of Trauma and Orthopaedics, Waterford Regional Hospital Ireland, Republic of Ireland Email aaronagiynn@gmail.com

Received: March 29, 2017| Published: June 01, 2017

\section{Case report}

A 71 year old post menopausal Caucasian woman with elevated BMI of 34 \& NIDDM, presented to the emergency department with acute severe bilateral thigh pain and inability to weight bear following a low impact fall from standing height. She also complained of an 18 month history of bilateral thigh, groin \& back pain, for which she was diagnosed with "fibromyalgia". She had been taking ibandronic acid $150 \mathrm{mg}$ by mouth monthly for the last 5 years for the treatment of postmenopausal osteoporosis. Plain radiographs of both limbs revealed a displaced fracture in mid-shaft region of both femori (Figure 1). Ibandronic acid was stopped and the patient underwent internal fixation with bilateral intramedullary reconstruction nails, locked proximally and distally (Figures $2 \& 3$ ). The patient made uneventful post-operative recovery and was subsequently discharged with outpatient follow-up.

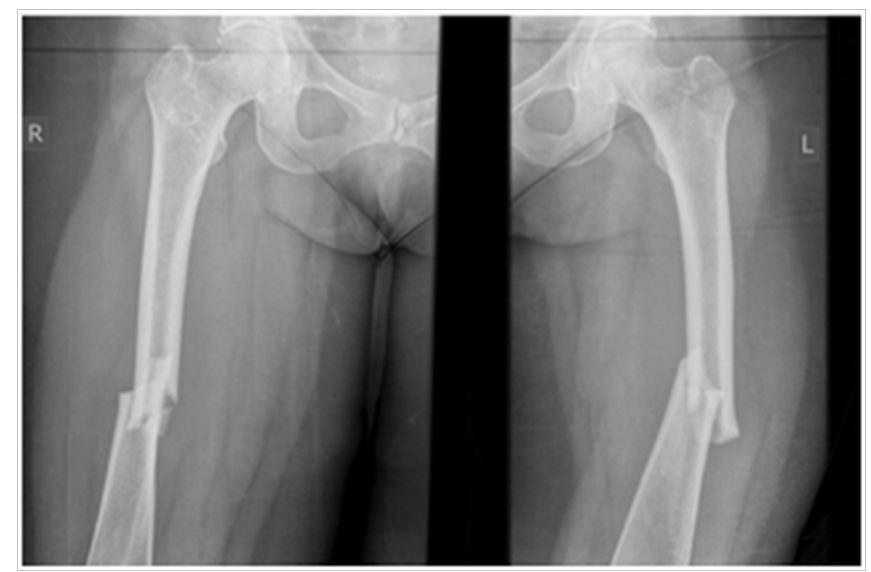

Figure I Atypical bilateral mid-shaft femoral fractures with lateral cortical thickening. 


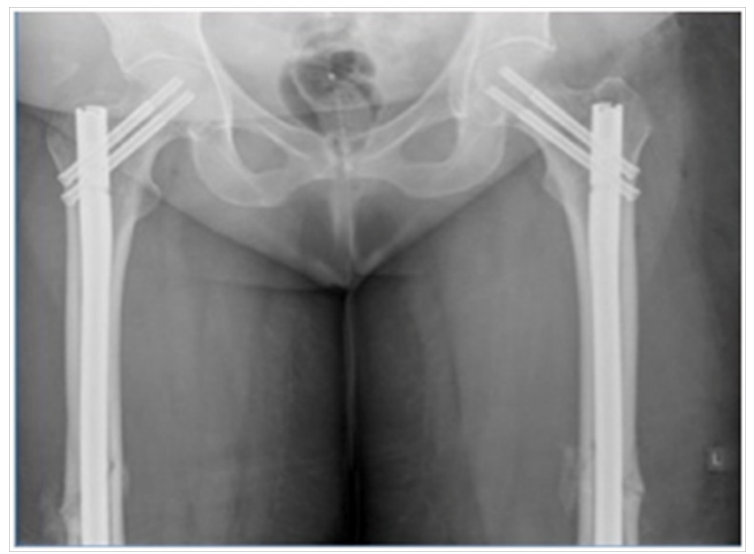

Figure 2 Post operative images.

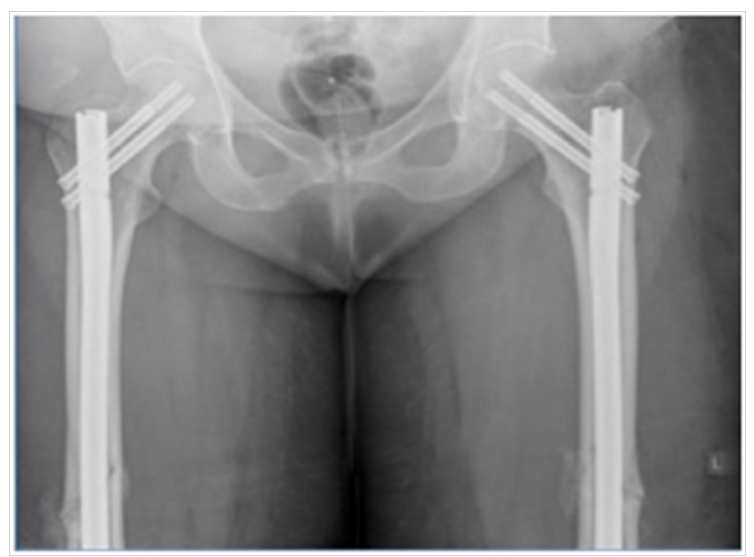

Figure 3 Post operative images.

\section{Discussion}

AFFs are seen most commonly in the proximal one-third of the femoral shaft but may occur anywhere along the femoral diaphysis. The fracture usually occurs spontaneously or following minimal trauma. The fracture may be complete, can have a transverse and short oblique pattern, often with the formation of a medial spike, and minimal comminution. In an incomplete AFF, there is a transverse radiolucent line in the lateral cortex. Both complete and incomplete AFFs are associated with periosteal stress reaction and thickening of the lateral cortex. ${ }^{7}$ This represents a failure of remodelling of the bone under tensile stress. There may also be generalised bilateral thickening of the medial and lateral cortices. Prodromal symptoms such as thigh and groin pain and are often observed.

As a subset of femoral fractures, AFFs are rare in the general population but there is emerging evidence that suggests that the incidence of AFFs is increasing with the increase in length of BP exposure. Data available from a large US health maintenance organisation (HMO) serving a population of 2.6 million people over the age of 45 , suggests that AFF incidence increased progressively from 2 per 100,000 cases per year for 2 years of BP use to 78 per 100,000 cases per year for 8 years of BP use. ${ }^{8}$

There a number of possible pathogenetic mechanisms associated with BPs and AFFs. These include alterations to the normal pattern of collagen cross-linking. ${ }^{910}$ micro damage accumulation, which may be due to the decrease in bone remodelling caused by BPs. ${ }^{11}$ reduced vascularity that could inhibit the repair of an impending stress fracture, which has been observed. ${ }^{5}$ in vitro models but not in animal models. ${ }^{12,13}$ increased mineralization and reduced heterogeneity of mineralization.

The optimal duration of BP therapy has not been established, and the balance of risks and benefits of long-term BP therapy is unclear. Based on current case reports and series, the median BP treatment duration in patients with AFFs is 7 years. ${ }^{6}$ Review of bisphosphonate use after five years of therapy has been proposed in the medical literature. ${ }^{5}$

AFFs secondary to BPs have been commonly described in the subtrochanteric region however bilateral mid-shaft fractures are rare. Some authors have reported an association between alendronic acid and femoral shaft fractures. ${ }^{14,15}$ However data regarding ibandronate is limited. Patel et al. ${ }^{16}$ reported a 62 year old female with femoral shaft fractures after 2 years of ibandronate therapy. ${ }^{16}$ Goddard et al. ${ }^{17}$ also reported a case of bilateral femoral fractures when their patient was switched to ibandronate after 16 year of therapy with a different bisphosphonate. ${ }^{17}$ The femoral fractures in their patient were not simultaneous. Our case is unique in its presentation due to its prolonged duration of therapy and bilateral simultaneous presentation.

Discontinuation of the bisphosphonates (drug holiday) has been proposed in the recent literature. A comprehensive review article by Lane et al. [18] recommend safely stopping the bisphosphonate treatment in low fracture risk group after 3-5 year of treatment. ${ }^{18}$ However in patients with high risk of osteoporotic fractures, bisphosphonate therapy should be continued or an alternative treatment should be instituted as the benefits outweigh the risks of late complications.

\section{Conclusion}

Prolonged bisphosphonate therapy ( $>5$ years) is associated with an increased risk of atypical femoral fractures. AFFs are a rare subset of femoral fractures but carry a significant level of morbidity and mortality. AFFs are characterised by unique radiographic features. More than half of patients reported with AFFs have had a prodrome of thigh or groin pain before their acute fracture. ${ }^{6}$ Patients on long term BP therapy who complain of thigh/groin pain require urgent radiographic evaluation of both femurs. Bone scan or MRI imaging may be necessary to identify an impending fracture. It is important to educate doctors and patients about these symptoms and their significance.

\section{Acknowledgments}

None.

\section{Conflicts of interest}

None.

\section{References}

1. Odvina CV, Zerwekh JE, Rao DS et al. Severely suppressed bone turnover: a potential complication of alendronate therapy. J Clin Endocrinol Metab. 2005;90(3):1294-1301.

2. Kumar G, Dunlop CC Effects of bilateral distal femoral stress in a patient on long-term pamidronate. Am J Orthop (Belle Mead NJ). 2013;42(7):326-328.

3. Jo YR, Kim HW, Moon SH, Ko YJ A case report of long-term bisphosphonate therapy and atypical stress fracture of bilateral femur. Ann Rehabil Med. 2013;37(3):430-432.

4. NOF's Newly Revised Clinician's Guide to Prevention and Treatment of Osteoporosis. National Osteoporosis Foundation, Washington D.C, USA, pp. 53. 2013 
5. Irish Osteoporosis Society Osteoporosis Guidelines for Clinicians. 2012

6. Shane E, Burr D, Ebeling PR, Abrahamsen B, Adler RA, Brown TD, et al. Atypical subtrochanteric and diaphyseal femoral fractures: report of a task force of the American Society for Bone and Mineral Research. $J$ Bone Miner Res. 2010;25(11):2267-2294.

7. Koh JS, Goh SK, Png MA et al. Femoral cortical stress lesions in longterm bisphosphonate therapy: a herald of impending fracture? J Orthop Trauma. 2010;24(2):75-81.

8. Dell R GD, Ott S, Silverman $\mathrm{S}$ et al. A retrospective analysis of all atypical femur fractures seen in a large California HMO from the years 2007 to 2009. ASBMR 2010 Annual Meeting Toronto, Canada. 2010

9. Zioupos P, Currey JD, Hamer AJ The role of collagen in the declining mechanical properties of aging human cortical bone. J Biomed Mater Res. 1999;45(2):108-116.

10. Vashishth D Advanced glycation end-products and bone fractures. IBMS Bonekey. 2009;6(8):268-278.

11. Mashiba T, Turner $\mathrm{CH}$, Hirano $\mathrm{T}$ et al. Effects of suppressed bone turnover by bisphosphonates on microdamage accumulation and biomechanical properties in clinically relevant skeletal sites in beagles. Bone. 2001;28(5):524-531.
12. Wood J, Bonjean K, Ruetz S et al. Novel antiangiogenic effects of the bisphosphonate compound zoledronic acid. J Pharmacol Exp Ther. 2002;302(3):1055-1061.

13. Deckers MM, Van Beek ER, Van Der Pluijm G et al Dissociation of angiogenesis and osteoclastogenesis during endochondral bone formation in neonatal mice. J Bone Miner Res. 2002;17(6):998-1007.

14. Capeci CM, Tejwani NC Bilateral low-energy simultaneous or sequential femoral fractures in patients on long-term alendronate therapy. $J$ Bone Joint Surg Am. 2009;91(11):2556-2561.

15. Cakmak S, Mahirogullari M, Keklikci K et al. Bilateral low-energy sequential femoral shaft fractures in patients on long-term bisphosphonate therapy. Acta Orthop Traumatol Turc. 2013;47(3):162-172.

16. Patel VC, Lazzarini AM Bilateral simultaneous femoral diaphyseal fractures in a patient with long-term ibandronate use. Orthopedics. 2010;33(10):775.

17. Goddard MS, Reid KR, Johnston JC et al. Atraumatic bilateral femur fracture in long-term bisphosphonate use. Orthopedics. 2009;32(8).

18. Villa JC, Gianakos A, Lane JM Bisphosphonate Treatment in Osteoporosis: Optimal Duration of Therapy and the Incorporation of a Drug Holiday. HSS Journal. 2016;12(1):66-73. 